\title{
ORIENTACIONES METODOLÓGICAS PARA EL ANÁLISIS FÍLMICO: SU APLICACIÓN EN UN DOCUMENTAL DE $1928^{1}$
}

\author{
Anna Gómez Mundó \\ Universitat de Vic \\ anna.gomez@uvic.cat \\ Josep Casanovas Prat \\ Universitat de Vic \\ josep.casanovas@uvic.cat
}

\begin{abstract}
RESUMEN
En este artículo se muestran las aplicaciones de orientaciones metodológicas para analizar documentos audiovisuales. A partir del trabajo desarrollado por el grupo de investigación, se consiguió observar, recoger y anunciar unas bases metodológicas para el análisis de imágenes, unas bases que están estrechamente relacionadas con las concepciones epistemológicas que las y los investigadores adoptan para llevar a cabo su trabajo ${ }^{2}$.Los análisis de documentos realizados posteriormente siguieron dichas indicaciones epistemológicas y metodológicas. A continuación, puede leerse cómo han sido aplicadas en un trabajo que estudia un documental del año 1928. La relación establecida entre las bases metodológicas y el documento a analizar es aquello que se pretende evidenciar, comentando el porqué de las decisiones tomadas durante el trabajo de análisis y estableciendo un diálogo con aquello que las fuentes artísticas aportan al análisis y articulación del discurso histórico.
\end{abstract}

Palabras clave: Metodología. Fuentes históricas audiovisuales. Análisis fílmico

\section{METHODOLOGICAL ORIENTATIONS FOR FILM ANALYSIS: THEIR APPLICATION IN A DOCUMENTARY OF 1928}

\begin{abstract}
This article shows the applications of methodological orientations for the analyses of audiovisual documents. From the work developed by the research group, we reached to observe, gather and announce some methodological bases for the analyses of images. These bases are related to the epistemological conceptions that are adopted by the researchers to go on with their work. The analyses of documents made afterwards led these methodological and epistemological orientations. So it can be read how they have been applied in a work which studies a documental of 1928. The relationship created between the methodological bases and the document to analyze is what we hope to put in evidence, telling the because of our token decisions during the work of analyses and supporting a dialog with everything what the artistic expressions give to the analyses and constructions of the historical discourse.
\end{abstract}

Keywords: Methodology. Audiovisual historic sources. Film analyses.

\footnotetext{
${ }^{1}$ Se trata del trabajo que se presentó para su futura publicación en la revista Ausa titulado "Una escola davant la càmera cinematográfica. La inauguració de l'edifici del grup escolar de Vinyoles a través d'una film documental de 1928". En prensa.

${ }^{2}$ El grupo de investigación está formado por Isabel Carrillo, Anna Gómez, Núria Padrós, Pilar Prat, Rosa Sambola y Jon Telford, siendo liderado por Josep Casanovas y Eulalia Collelldemont. El grupo forma parte del GREUV (Grup de Recerca Educativa de la Universitat de Vic).
} 


\title{
ORIENTAÇÕES METODOLÓGICAS PARA UMA ANÁLISE FÍLMICA: SUA APLICAÇÃO NUM DOCUMENTÁRIO DE 1928
}

\begin{abstract}
RESUMO
Este artigo tem por objetivo apresentar a aplicação de orientações metodológicas para analisar documentos audiovisuais. A partir do trabalho desenvolvido pela equipe de pesquisa se observou, coletou e finalmente se elaborou uma base metodológica para analisar as imagens. Uma base que está diretamente relacionada com as concepções epistemológicas das quais a equipe realizou a pesquisa. A análise dos documentos efetuada posteriormente seguiu estas indicações, como se observará no estudo documental do ano 1928. O objetivo é evidenciar a relação entre as bases metodológicas e o objeto de pesquisa, descrevendo o porquê das decisões tomadas durante o trabalho empírico de análise e estabelecendo um diálogo com as referências que as fontes artísticas aportam, logo articulando com o discurso histórico.
\end{abstract}

Palavras-chave: Metodologia. Fontes históricas audiovisuais. Análise de filmes.

\section{ORIENTATIONS METHODOLOGIQUES POUR L'ANALYSE FILMIQUE: LEUR APPLICATION DANS UN DOCUMENTAIRE DE 1928}

\section{RÉSUMÉ}

Cet article décrit l'application de quelques orientations méthodologiques afin d'analyser des documents audiovisuels. A partir du travail développé par le groupe de recherche, nous avons pu observer, recueillir et annoncer des bases méthodologiques pour l'analyse d'images, des bases qui sont étroitement liées aux conceptions épistémologiques que les chercheurs prennent pour mener à bien leur travail. L'analyse de documents effectuée ensuite a suivi ces indications épistémologiques et méthodologiques. Ci-dessous, vous pouvez lire comment elles ont été appliquées dans un travail étudiant un documentaire de 1928. La relation établie entre les bases méthodologiques et le document à analyser est ce que nous cherchons à mettre en évidence, en commentant les raisons qu'il y a derrière les décisions prises pendant le travail d'analyse et en établissant un dialogue avec les sources artistiques qui contribuent à l'analyse et à l'articulation du discours historique.

Mots-clés: Méthodologie. Sources historiques audiovisuelles. Analyse de films.

\section{PRESENTACIÓN DEL DOCUMENTO DE TRABAJO}

El documental que analizamos se rodó el 9 de setiembre de 1928 en Vinyoles d'Orís, un pueblo de la provincia de Barcelona. Su duración es de 9 minutos y 40 segundos, las imágenes que muestra sonen blanco y negro, muda (al estilo de los documentales específicos de ese periodo) y muy bien editada.La inauguración del edificio nuevo de la escuela pública del pueblo fue lo que motivó la realización de la filmación. Se aprovechó la ocasión para bendecir también la bandera del sometent, hecho que desencadenó interesantes reflexiones por 
parte del grupo ${ }^{3}$. Los dos festejos -la inauguración de la escuela y la bendición de la banderaconstituyen el contenido principal de la filmación. Gran parte del protagonismo del documental recae en las figuras de los Condes de Lacambra, condes que ejercieron de mecenas del proyecto sufragando los gastos de la construcción de la nueva escuela ${ }^{4}$. Precisamente fue la condesa, la señora Teresa Estany, quien apadrinó la bandera del sometent.

Acompañaban a los Condes las principales autoridades eclesiásticas y militares de Cataluña y de la Diócesis, como el obispo de la ciudad de Vic, Joan Perelló, y el capitán general de Cataluña, Emilio Barrera. Es importante subrayar que durante la Dictadura de Primo de Rivera, período en el que se ubican los festejos filmados objeto de nuestro estudio, el capitán general de Catalunya representaba la máxima autoridad político-militar del territorio. Ese dato da cuenta de la carga simbólica que se atribuyó al evento.

El documental estudiado tiene una trascendente importancia debido a que no se han conservado muchos films documentales de índole educativa realizados durante la década de los años 20 del siglo XX en el ámbito del Estado Español. ${ }^{5}$

\section{DESCRIPCIÓN DE LA INVESTIGACIÓN}

El principal objetivo del trabajo consistía en analizar qué imagen se proyectaba de la educación y de las escuelas de la época de la dictadura de Primo de Rivera a través del incipiente cine de carácter documental que en aquellos años empezaba a formarse y a tener presencia pública y, por lo tanto, podía ejercer cierta influencia en la población que los visionaba $^{6}$. El reto que presentaba el proyecto era la poca trayectoria de experiencias que hayan tomado como fuente de información los documentos audiovisuales, siendo aún menos explorada en su aplicación de documentales de los comienzos de la historia del cine ${ }^{7}$. Uno de los principales propósitos que emprendimos, por lo tanto, fue dejarnos guiar por los movimientos de la cámara cinematográfica, poniendo especial atención tanto en qué se fijaba como en qué dejaba de lado. Proceder de esta forma nos hizo dar cuenta de la poca o nula

\footnotetext{
${ }^{3}$ El "sometent" era un cuerpo civil armado, de carácter paramilitar, propio de Catalunya. Sus orígenes se encuentran ya en la época medieval. Durante la dictadura de Primo de Rivera se promovió este cuerpo atribuyéndole funciones de control social, un cuerpo, pues, dedicado a velar por el régimen dictatorial.

${ }^{4}$ Todavía hoy la escuela pública del pueblo lleva el nombre de sus mecenas "Comtes de Lacambra".

${ }^{5} \mathrm{La}$ referencia de todos los que hemos podido registrar puede consultarse en la página virtual del Museu Universitari Virtual de Pedagogia de la Universitat de Vic: www.uvic.cat/museu-virtual.

${ }^{6}$ Es importante considerar que por aquellas fechas este tipo de documentales eran de obligado pase en los cines antes de la proyección de las películas de ficción.

${ }^{7}$ Para ampliar el conocimiento de este elemento, es interesante la lectura de Sánchez-Biosca, Vicente; Tranche, Rafael (2006) NO-DO. El tiempo y la memoria. Madrid: Cátedra
} 
presencia de personas directamente relacionadas con la escuela. Ni maestros ni alumnos aparecen en él. Sólo aparecen autoridades relacionadas con el ámbito educativo, pudiéndose identificar al rector de la Universitat de Barcelona, el señor Eusebio Díaz, y a la inspectora de enseñanza Ángela Furnich. Así pues, tomamos como una parte importante de la voz discursiva y de la producción discursiva a la cámara, una de las principales protagonistas del soporte fílmico. La cámara y sus movimientos iban dándonos pistas de cómo se entendía y se proyectaba la educación a través de la inauguración de una escuela.

Es de especial importancia subrayar la disposición a dedicar tiempo y atención a las posibles funciones o finalidades con las que se producían los documentales fílmicos. En no pocas ocasiones, nos hemos percatado del influyente rol propagandístico que ejercían, fuera porque la intención inicial de su realización y proyección ya contenía la voluntad de difundir propaganda, fuera porque se le atribuyera a posteriori a raíz de su contenido.

Ha sido complementando las fuentes escritas con las audiovisuales cómo hemos podido llegar a una de las conclusiones más sólidas de la investigación acerca de este periodo histórico. El minutaje dedicado al edificio desnudo, sin presencia de personas ante él o dentro de él, nos hace pensar seriamente en que la imagen pensada de lo que se quiere mostrar de la escuela es su parte más material, confirmando la hipótesis que la intervención en el ámbito educativo de la dictadura se concentró más en aumentar la cantidad de sedes escolares que no en la calidad de las metodologías de enseñanza. Captar imágenes desde el interior de un edifico conlleva algunos problemas técnicos, sobretodo de iluminación, pero la luz que los grandes ventanales del edificio permitían que entrase nos hace pensar que con preparación previa - si hubiera habido voluntad de ello- habría sido posible hacerlo. Afirmamos las posibilidades técnicas apoyándonos en otros documentos que sí contienen imágenes de estancias interiores, como se puede consultar en ¿Qué es España?,Valencia, protectora de la infancia o en el Grupo Escolar Cervantes. La no inclusión de imágenes del interior de la escuela obedece, sin duda, a unas intenciones determinadas que tenían mucho que ver con la política educativa del régimen de Primo de Rivera. Era una política eminentemente efectista, de fachada, ocupada en una clara función propagandística. Así pues, parece que el mensaje que se quería transmitir era que aquello importante de la educación era sus edificios, de manera que maestras y alumnos quedaban en un segundo plano. Las pocas veces que aparecen 
en el film lo hacen situados en los márgenes de los espacios donde se desarrollan los actos y de los encuadres de la cámara ${ }^{8}$.

\section{LA PARTICIPACIÓN DE LAS DISCONTINUIDADES EN EL PROCESO INVESTIGATIVO}

A la hora de pensar en la realización del análisis de documentos, hay diversos aspectos que debemos poner en consideración. A lo largo de la historia, sabemos que hay elementos que perviven y otros que sufren cambios, mutaciones o incluso desaparecen. Del seguimiento de estos ejes es a lo que llamamos continuidades y discontinuidades de la historia. Pues no sólo es importante identificar y estudiar las categorías que van conformando la investigación, sino también la calidad y cantidad de su presencia a lo largo del tiempo, tanto del periodo estudiado como del que nos separa de él.

Aquello que deseamos plantear en este apartado atañe precisamente a aquello que cambia, muta, se invierte o desaparece. Así pues, justo en el momento de tomar como fuente de investigación un artefacto cultural, y más si proviene de otra época, sabemos de antemano que inevitablemente van a aparecer unas discontinuidades a las que debemos atender con seriedad y rigor.

Las líneas de discontinuidad ontológica y epistemológica no se pueden obviar: ni conocemos de primera mano la realidad representada en el film ni los detalles de las circunstancias en las que éste fue gravado. Percatarse de ello es importante, y la atención a esa discontinuidad puede trasladarse en la escritura del informe que se escribe. Pocas afirmaciones rotundas terminan por aparecer en el texto, mayormente escrito en condicionales y suposiciones que se explicitan aportando los elementos que han conducido a apuntar el elemento que se expone.

La discontinuidad ontológica más potente que hallamos en el análisis del documental protagonista de este artículo la encontramos en la concepción de escuela. La significación de escuela de una y otra época ha sufrido cambios profundos desde entonces, y aquél edificio lleno de criaturas con materiales en las manos, repartidos de manera irregular por un espacio abierto o cerrado, etc. que ahora proyectamos al pensar el concepto escuela se presenta como un edificio vacío de niños, con una fachada regia, sin ningún material didáctico a la vista y disfrutada eminentemente por personas adultas bien trajeadas.

\footnotetext{
${ }^{8}$ Esta característica se repite en otros tres films realizados con motivo de la inauguración de las escuelas de los pueblos de Carlet, Mequinensa y Barcelona. (Prat, Casanovas; Collelldemont, Eulàlia, 2016)
}

Rev. Iberoam. Patrim. Histórico-Educativo, Campinas (SP), v. 3, n. 1, p. 34-48, jan./jun. 2017 
Una segunda discontinuidad se refiere a la dimensión diacrónica: el sujeto investigador y el objeto investigado mantienen una distancia temporal entre sí que influye directamente en las posibilidades de compartir con total seguridad las interpretaciones que pueden desprenderse del documento. En el caso que nos ocupa, son ochenta y nueve años los que median entre el documento y la fecha de su análisis. Otra ocasión para añadir un ejemplo de discontinuidad ontológica: si una época se sitúa en plena dictadura, afortunadamente los investigadores no han vivido en sus carnes la experiencia de desarrollar su vida en un marco de organización política tan indeseable. Es con estas disimilitudes que analizamos, interpretamos y explicamos las imágenes, disimilitudes que establecen límites a la propia investigación a la vez que la sitúan y contextualizan.

A estas dos discontinuidades debe añadirse el desconocimiento total o parcial del formato narrativo del soporte utilizado, formato todavía novedoso dentro del ámbito históricoeducativo. La escritura y la lectura han sido las formas que con más frecuencia han sido las ayudantes de los proyectos de investigación. Las imágenes producen otro tipo de narraciones y se orientan por gramáticas distintas a las de la escritura. Si la imagen se presenta en forma de dibujo contiene unas particularidades diferentes a si la imagen está en formato fotografía. La cosa también cambia cuando la imagen está en movimiento, como pasa en los documentos audiovisuales, sean películas, reportajes, anuncios o documentales. Para nuestro propósito, fue necesario aprender a relacionarnos con los fotogramas, seguir e interpretar los movimientos de la cámara, qué encuadres hacía y preguntarnos el por qué el enfoque recaía sobre un grupo y no en otro.

Por fortuna, en este documento de trabajo no apareció con la fuerza que sí lo hizo en otra ocasión otra discontinuidad destacada que se da cuando las fuentes son producidas por una etapa de edad distinta a la que tiene la generación de investigadores que la realiza ${ }^{9} . \mathrm{Su}$ trabajo con el simbólico no sólo se da en una temporalidad distante a la nuestra, sino que también se da en una etapa vital de la que nosotros ya salimos hace años, además que la experiencia de ser niño y de ser niña de unos y otras no es nunca la misma debido a la carga de singularidad que da una especificidad única a cada experiencia. Aun así, el ejercicio que nos obligó a hacer esta cualidad de las fuentes documentales fue apasionante y muy formativo

\footnotetext{
${ }^{9}$ Esta discontinuidad constituía la principal característica de las fuentes con las que trabajamos en una investigación anterior consistente en analizar dibujos realizados por niños y niñas en una escuela de Barcelona durante la guerra civil española (1936-1939). La investigación llevó tres años de trabajo (2011-2013) y dio lugar a diferentes publicaciones. El proyecto se sostuvo gracias a la ayuda del Ministerio de Educación y Ciencia del gobierno español y llevó el nombre de "Documentación, interpretación y difusión digital del patrimonio educativo producido entre 1936-1939 en las escuelas de Barcelona. Los dibujos de la infancia" Programa I+D+I (EDU2010-20280).
} 
a nivel epistemológico. La humildad de aceptar los vacíos de conocimiento y los límites que la distancia generacional, e incluso la que pone la misma subjetividad singular de cada quién, fue un aspecto que ya no hemos podido abandonar en los futuros trabajos. Las singularidades que aparecen, aquello que supone una disrupción, un elemento único y marginal en tanto que no tiene carácter de representatividad, devienen elementos especialmente valiosos al trabajo de investigación puesto que atenderlas y considerarlas permite que nos enseñen las brechas discursivas de nuestro relato histórico.

Reconocer nuestros límites, lejos de dejarnos con impotencia ante el documento, es un faro que nos acompaña y ayuda a lo largo del proceso de realización y de difusión de la investigación.

\section{IMPLICACIONES DE CONTEMPLAR LAS DISCONTINUIDADES}

Las gramáticas dispares de las narrativas utilizadas en los documentos históricos tienen, no obstante, un punto en común. Ambas comparten la voluntad de dar sentido -sentido que no siempre coincide con la verdad- de aquello que significa o ha significado lo acaecido.

Las narraciones no son simples maneras de contar las cosas, sino que condicionan cómo aprehendemos y construimos el mundo. Las narraciones son aquellos instrumentos a través de los cuales damos sentido a nuestro mundo, constituyéndolo como significativo para nosotros. La narración es, pues, una de las principales herramientas de construcción de la realidad simbólica. (CABRUJA, 2000, p.84).

En efecto, quien encarga la filmación, quien la realiza y quien participa en las escenas filmadas tienen una idea de qué significación quieren o deben dar en esta producción fílmica. En este caso concreto, sabiendo sin duda que los condes de Lacambra encargaron la filmación del acto de inauguración, desconocemos el autor material de la película. Las consultas al Arxiu Nacional de Catalunya no dieron ningún resultado. Tampoco lo obtuvimos consultando directamente a la familia, quienes confesaron desconocer quién o quiénes fueron los autores de la filmación.

De la misma manera, quien lo visualiza en su época o después de un siglo también realiza el trabajo simbólico de otorgar significado ala realidad que el relato le presenta ante sí. En este caso, la significación peyorativa del grupo de investigación en relación al periodo dictatorial nos situaba a considerar cualquier autoridad presente en las imágenes como representante de 'los malos', 'los opresores', etc. y sus acciones directamente atribuibles a la función de control de un régimen represor. Tener presentes los aspectos de nuestra comunidad imaginada ayudó a la hora de no caer en sobreinterpretaciones o, por ejemplo, a poner entre 
paréntesis las primeras interpretaciones, suspendiéndolas hasta que no tuvimos nuevos datos con los que sostenerlas.

Ser conscientes de este aspecto nos lleva a tomar precauciones ante las diferentes significaciones que vamos atribuyendo a las imágenes observadas. Las precauciones deben tomarse porque es evidente que el resultado de los procesos de significación de todas las personas implicadas en el documento fílmico no es casi nunca único, sino que casi siempre podemos afirmar que las significaciones son plurales. Este elemento tiene que ver con la advertencia que Burke (2006) hacía en relación a la práctica de adjudicar una homogeneidad cultural a una comunidad concreta. Lo que sí podemos hacer es contrastar aquello hallado en el documento de trabajo con otras producciones de las mismas características para ver qué elementos aparecen como continuidades entre sí. Este ejercicio puede dar lugar a los fundamentos argumentales con los que apoyar nuestras observaciones. En el caso concreto que nos ocupa, el análisis del documental tuvo lugar después de realizar una amplia y extensa filmografía del período histórico al que pertenecía la filmación ${ }^{10}$.

El motivo que nos obliga a ir más allá de los documentos investigados y, por lo tanto, a consultar otras fuentes de información que complementen y amplíen el conocimiento que vamos articulando durante el proceso de investigación tiene que ver con el imaginario de la comunidad y la comunidad imaginada. Los dos conceptos atañen a aquello que dos comunidades imaginan: una lo hace de sí misma -el imaginario de la comunidad- y la otra lo hace de la que está hablando -la comunidad imaginada-. En efecto, la proyección que da el documento de aquella sociedad no está desligada de la proyección que sus autores y productores querían darle. De igual manera, el modo en el que los miembros del grupo de investigación se relacionan con la época estudiada mantiene una estrecha relación con aquello que saben de la época, de qué y cómo se la han contado, de qué y cómo han ido construyendo el relato histórico de aquella época. Ello va a constituir un filtro que va a interponerse entre nosotros y el documento a partir del cual investigamos. Este filtro nos conduce a que fácilmente designemos como más relevantes aquellos objetos, gestos, rituales, colores, tonos, etc. que más se acercan a los que están en nuestra comunidad imaginada.

Así pues, está claro que estos elementos discursivos son otros de los que también debemos poner encima de la mesa y saber que ponerlos entre paréntesis no va a restar, sino a

\footnotetext{
${ }^{10} \mathrm{El}$ trabajo se enmarcó en el proyecto de investigación "Revisión y análisis de documentales propagandísticos y anuncios audiovisuales educativos producidos entre 1914-1939 en España.", financiado por el Ministerio de Ciencia e Innovación del gobierno español (EDU2013-48067) durante el periodo 2014-2016.
} 
aguzar más la vista y el oído en la visualización y posterior análisis e interpretación de la película.

Saber que en una misma época existen diferentes opciones y deseos de significar y proyectar su tiempo presente -sea la época que sea- nos lleva a considerar la realidad estudiada como aquella en la que coexisten diferentes imaginarios, aunque unos hayan sido más divulgados y estudiados que los otros.

Como hemos planteado, la consulta de otras fuentes documentales es necesario para observar la complejidad y pluralidad de perspectivas con las que podemos aproximarnos al objeto de estudio. Sería seguir la orientación metodológica de ayudarse de distintas fuentes para comprender mejor el documento que se desea analizar. Libros de historia, registros de archivos, fotografías de la época, documentos testimoniales tales como diarios personales, noticias y reportajes periodísticos, trabajos escolares, revistas, canciones, pinturas, novelas, novelas históricas, etc., son algunas de las fuentes -algunas de un claro carácter artístico- de las que podemos y nos hemos ayudado a la hora de ir articulando un discurso histórico más ajustado y riguroso de aquello estudiado ${ }^{11}$. Esta fase de la investigación es cuando el modo más pertinente de definir el trabajo de investigación es el de trabajo de búsqueda. Ojos, oídos y mente están inquietos y buscan a su alrededor todo aquello que pudiera tener relación con lo que nos está ocupando el tiempo. Toma importancia todo aquello relacionado con el lenguaje fílmico, con la época histórica, con la historia del cine, con las dimensiones socioeconómicas y pedagógicas de la realidad estudiada. Todo ayuda a la comprensión o, al contrario, al desconcierto. Sea como sea, no debe descartarse ningún elemento que nos pueda ayudar a conseguir nuestro objetivo de conocer más y mejor un elemento de la realidad. Sólo la falta de tiempo o las magnitudes de las dimensiones que dé a la investigación pueden ser motivo de descartes. Y cuando esto ocurre, debe decirse en el informe final de investigación.

\section{LA IMPORTANCIA DEL CONTEXTO CON TODAS SUS CARAS}

Si algo resulta evidente, es que los documentos fílmicos son testimonios históricos y expresiones culturales creadas en una época concreta. La realidad cultural, política, económica y social no está desligada del corpus simbólico que dominaba en tal época

\footnotetext{
${ }^{11}$ Cabe destacar que en este proyecto ha sido de gran importancia las aportaciones a la investigación de unas fuentes documentales privilegiadas. Tuvimos la posibilidad de visionar documentos fílmicos privados de la familia Lacambra, actualmente custodiados por la Filmoteca de Catalunya. Uno de los consultados y que más colaboró en la comprensión del contexto fue "Visita del rei a la colònia de la Farga, familia Lacambra-Masies de Voltregà ”. Número de registro 05136.P/02
} 
histórica, conscientes siempre que la realidad mayoritaria no excluye la posibilidad de cohabitar con otras realidades más o menos diferentes a la dominante.

\begin{abstract}
La imagen fotografiada ha sido escogida para su conservación. La imagen dibujada contiene la experiencia de mirar. Una foto es la prueba del encuentro entre un suceso y un fotógrafo. Un dibujo cuestiona sin prisa la apariencia de un suceso y, al hacerlo, nos recuerda que las apariencias son siempre una construcción con una historia. (Nuestra aspiración a la objetividad solo puede derivarse de admitir la subjetividad). Utilizamos las fotografías llevándolas con nosotros, en nuestras vidas, nuestros razonamientos, nuestros recuerdos; somos nosotros quienes las movemos. Por el contrario, un dibujo o una pintura nos obligan a detenernos y a entrar en su tiempo. (BERGER, 2011, p.55).
\end{abstract}

Por ello, a la hora de analizar el documento, fue imprescindible considerar los elementos políticos y sociales más relevantes tanto del pueblo de Vinyoles d'Orís como del país, España. La presencia o ausencia de personas en los actos filmados era explicable, en parte, por el conocimiento de los aspectos más característicos de aquel año. Los protagonistas del film provenían tanto de la misma población como del gobierno del momento, lo cual implica ampliar el foco de mira e interrogarse acerca de la relación que estas personas mantenían entre sí y con el resto de la población: ¿Eran respetados? ¿Eran queridos? ¿Existían envidias o rencores entre ellos? ¿Su presencia en actos civiles era habitual o extraordinaria? Un dato relevante que encontramos en el transcurso de la investigación fue la estrecha relación de amistad, incluso de intimidad, que mantuvieron los condes con el rey Alfonso XIII de España, especialmente Francesc Lacambra, el conde. Tanto es así que entre las diferentes hipótesis que nos planteamos para explicar la generosidad demostrada por la familia Lacambra hacia el pueblo de Vinyoles d'Orís - destacar su condición de industriales metalúrgicos boyantes por encima del resto de los industriales y altos cargos del municipio y/o procurar un buen centro educativo para los hijos de los obreros de la fábrica que tenían en el pueblo- también contemplamos la posibilidad de haberlo hecho para obtener un título nobiliario de la casa real española, como así acabó sucediendo.

Describir los detalles, profundizar en el conocimiento de la realidad de la época, de los personajes citados, ampliar el foco a un contexto más amplio -tanto temporal como geográfico-del que aparece estrictamente en el documento, etc. son acciones imprescindibles para hacer una aproximación lo más crítica posible al objeto de estudio. Es por ello que buena parte de los informes finales de las investigaciones - también del artículo resultante del análisis del documental del que estamos hablando- dedican numerosas páginas a los aspectos contextuales. 
Prestar atención a las vidas de los personajes que aparecen en los documentos, al estilo arquitectónico del edificio, a la situación de la realidad educativa del pueblo y del país y a la situación política que gobernaba y bajo qué planteamientos ideológicos lo hacía, entre otros elementos, pone de relieve la necesidad casi imprescindible de que participen del trabajo investigadores procedentes de diferentes áreas de estudio. En nuestro grupo, la formación en psicología, historia y pedagogía de sus miembros ha aportado una riqueza de matices que ha colaborado en la voluntad de afinar con rigor nuestros análisis. El carácter multidisciplinar del equipo ha sido un elemento importante para el desarrollo de la investigación, y más lo ha sido el trabajo interdisciplinario que ha puesto en relación las reflexiones, dudas y saberes de unas y otros. Ahí está algo que todavía se da con poca frecuencia en nuestro mundo académico, así es, aunque el número de grupos multidisciplinarios va en aumento, no lo hace de igual manera la práctica de hacer entrar en diálogo la pluralidad de perspectivas que dicha variedad formativa aporta. Pasar de la multidisciplinariedad a la interdisciplinariedad requiere una actitud de trabajo que precisa del encuentro con el otro y de la discusión conjunta, dando forma a lo que se parecería a un taller de investigadores que trabajan juntos saliendo de la inercia de juntar los pedazos elaborados separadamente por cada uno de ellos.

Un modelo de organización que colabora en la puesta en común de los saberes y del diálogo desde las distintas perspectivas académicas - diálogo que constituye la base de varios aprendizajes susceptibles de hacer por parte de los miembros del equipo investigador- es el que aparece bajo la forma de los seminarios de trabajo. Seminarios de trabajo que también pueden llamarse seminarios de estudio, de debate, de intercambio y de acompañamiento ${ }^{12}$. En las reuniones regulares que realizamos no sólo nos convocábamos a nosotros, sino que en más de una ocasión pedimos la colaboración de colegas no participantes en nuestro proyecto pero que creíamos que podían aportarnos perspectivas y conocimientos valiosos para nuestro propósito. Y así fue. Fue una oportunidad para constatar que la interdisciplinariedad es mucho más que un modelo de investigación al uso, y que su pertinencia en proyectos de investigación de naturaleza similar al nuestro es incuestionable. Para el trabajo que estamos explicando, fue de gran valor el encuentro de la mirada de un historiador con la de una pedagoga. Las perspectivas no sólo complementaban análisis, sino que los desbordaban para incorporar aspectos que para uno o para la otra habían pasado desapercibidos $\mathrm{y}$, sin embargo, formaban parte del relato histórico-educativo del documental.

\footnotetext{
${ }^{12}$ A modo de ejemplo, enumeramos algunos de los seminarios realizados: "Discursos de memòries a partir de les imatges", "La exploración de ideas y de metodologías a partir del análisis de imágenes. Conversando con Burke", "Aportaciones de la Historia Cultural en la investigación pedagógica".
} 
La misma diversidad de disciplinas pone de relieve algo necesario incluso cuando los miembros del equipo comparten itinerarios formativos. Eso es, cualquier investigador debe dar a conocer la posición epistemológica desde la que parte. La articulación de las diferentes narraciones fruto de las interpretaciones dispares da lugar, entonces, a un informe cuyo contenido no es neutro ni siempre uniforme. Tampoco será necesariamente coincidente con la memoria heredada, ya que el trabajo interpretativo puede que haya apuntado elementos descartados o menospreciados hasta el momento por parte de la comunidad académica. Es más, enfocar con atención las partes más olvidadas, ambiguas o descartadas por la tradición investigadora deviene útil en tanto puede aportar una perspectiva mucho más holística del hecho estudiado. Con esas palabras lo expone Burke (2012, p.179):

Descartar conocimientos puede ser deseable o incluso necesario, al menos hasta cierto punto, pero no deberíamos olvidar las pérdidas al igual que las ganancias. De ahí la necesidad que sienten los historiadores de la cultura de estudiar lo que se ha desechado a lo largo de los siglos, la basura intelectual que incluye información, ideas e incluso personas. A menudo se ha observado que los historiadores se decantan generalmente por los ganadores, a pesar de la necesidad de reconstruir la $<$ visión de los derrotados $>$ con el fin de entender el pasado.

Sin embargo, el encuentro y la consideración de dichos aspectos no suceden por casualidad. Para ello será necesario adoptar una actitud de apertura a aquello inesperado y/o desconocido.

\section{LA NECESARIA ACTITUD DE APERTURA}

Cuando uno empieza el camino de comprender mejor un aspecto de nuestra historia, no sabe de antemano con qué se encontrará. Puede haberse planteado unas hipótesis, debe saber de qué conocimientos previos parte, puede explicitar aquello con lo que le gustaría encontrarse. Puede apoyarse en investigaciones anteriores - suyas o de otros colegas- para diseñar a grandes rasgos el recorrido por el que quiere caminar, incluso puede pensar que va a pasarle lo mismo que en el trabajo similar que hizo el año anterior. Bien. Puede hacer todo esto, como también nosotros lo hicimos en parte al plantearnos el trabajo de análisis del documental que nos ocupa. Pero, como decíamos, nunca podemos asegurar saber qué vamos a encontrar durante la investigación. Lo que implica esta certidumbre es la obligación de estar atentos a lo que los distintos hallazgos van indicando o insinuando, porque el rigor metodológico requiere sensibilidad para escuchar y tener en cuenta no sólo lo esperado, sino también aquello imprevisto. La sensibilidad aparece con la apertura a los datos, a las brechas de significado, a los testimonios divergentes al conocimiento asentado acerca de la cuestión, y

Rev. Iberoam. Patrim. Histórico-Educativo, Campinas (SP), v. 3, n. 1, p. 34-48, jan./jun. 2017 
también aflora, o debe aflorar, ante las contradicciones discursivas con las que nos encontramos. Algo así nos sucedió cuando en una fase muy avanzada de la investigación nos percatamos de una distorsión en el estilo de diseño del edificio atribuido al arquitecto Josep M. Pericas. Leyendo una biografía del arquitecto a quien se encargó el proyecto de las escuelas, uno de los más prestigiosos de Vic, debimos poner entre paréntesis la autoría ampliamente dada por descontada ${ }^{13}$. Además, accediendo a los planos del proyecto inicial y visionando las imágenes del documental y documentos gráficos posteriores a su proceso de construcción, nos percatamos que los edificios escolares presentaban notables diferencias en relación al proyecto inicial. Ni se construyeron las viviendas para los maestros que tenían que ubicarse en el primer piso del edificio, ni se observaban las entradas independientes según el sexo de los escolares. El sello distintivo del zócalo de piedra que siempre identificaba la obra de Pericas, el arquitecto, no aparece en la fachada del edificio y sí lo hace, en cambio, la moldura de bloques de piedra rectangulares, pulidos y con los cantos vivos en las esquinas del edificio y en sus aberturas (puertas y ventanas). Esta característica no se encuentra en ningún otro proyecto del arquitecto vicense.

Así pues, poner en duda nuestras primeras observaciones o ser desmentidos por nosotros mismos es una situación a la que debemos abrirnos necesariamente si aceptamos que la investigación es una experiencia abierta a los imprevistos y a las sorpresas. La misma fuente de imagen, con su naturaleza de proyección de significados múltiples, implica una pluralidad de interpretaciones que la hacen rica en este tipo de situaciones que la convierten en una fuente documental calidoscópica y repleta de potencial de significación.

\section{SOSTENER UNA METODOLOGÍA}

Con todo lo dicho hasta ahora, creemos que se hace evidente la obligación de contemplar continuamente la dimensión ética de la práctica investigadora. Además de los argumentos casi prescindibles para defender que la ética acompañe las decisiones y las acciones emprendidas para llevar a cabo la investigación -argumentos compartidos por una amplia mayoría de colegas-, queremos señalar que es precisamente el seguimiento de una actitud ética aquello que aporta rigurosidad a la investigación. La dimensión ética trabaja a

\footnotetext{
${ }^{13}$ Nos estamos refiriendo a la lectura de CATASÚS, Aleix (2016) Josep Maria Pericas i Morros. Arquitecte noucentista (Vic, 1881 - Barcelona, 1966). Vic: Patronat d'Estudis Osonencs.
} 
favor de la rigurosidad tanto del proceso como de la presentación final de los resultados de la investigación realizada.

No podemos olvidar que la narración histórica es una propuesta más que se añade a las que pretenden narrar un conjunto de hechos y de representaciones culturales de una sociedad en un momento histórico. Y narrarlos con coherencia. Lo que sucede a veces es que buscando la coherencia se omiten los saltos de comprensión o los aspectos borrosos que se han hallado. Puede que se haga por no poner obstáculos a la voluntad de acercarse a la verdad, pero en seguida vemos que lejos de aproximarnos aportamos más ambigüedades y obstáculos para una futura mejor comprensión del hecho. Asociar el hecho de plantear las dudas nacidas de la investigación con la mala praxis investigadora es un error que lleva a dar por descontados hechos que no son ni mucho menos tan simples ni se dan de forma tan compacta como parecen a priori.

La humildad y la capacidad de crítica y de autocrítica de los autores son elementos que en lugar de debilitar el valor de la investigación la refuerza. Veamos qué nos dice acerca de ello Ricoeur (1999, p.46):

\begin{abstract}
Vincular la historia explicativa, de este modo, a una lógica de lo probable no supone un debilitamiento de su efecto crítico. No hay que olvidar que lo probable ocupa una posición intermedia entre la prueba, que convence debido a su necesidad intelectual, y el sofisma, que seduce mediante los artificios del lenguaje. El hecho de aproximar la historia a una lógica de lo probable no sólo no debilita su función crítica, sino que la refuerza, la convierte incluso en un recurso terapéutico. En este nivel, el entendimiento se acostumbra a la pluralidad de relatos sobre los mismos acontecimientos y aprende a "contar de otra manera". Esto no es todo, la contraposición de modos contrarios de encadenamiento puede llevarse a cabo conforme a un propósito pedagógico firme, el de aprender a contar nuestra propia historia desde un punto de vista extraño al nuestro y al de nuestra comunidad. "Contar de otra manera", pero también dejarse "contar por otros".
\end{abstract}

He aquí la riqueza del trabajo investigativo: contar y dejarse contar.

La curiosidad de saber más, aquello que con más fuerza debería ser lo que alentara todo proyecto de investigación, nos ensancha perspectivas, nos da más elementos para mirar y pensar mejor para, ojalá, emprender acciones más sensatas y justas en nuestro presente, también configurador de historia. De historias.

\title{
REFERENCIAS
}

BERGER, John. Sobre el dibujo. Barcelona: Gustavo Gili, 2011.

BURKE, Peter. Historia social del conocimiento. Vol. II. De la Enciclopedia a la Wikipedia. Barcelona: Paidós, 2012. 
. ¿Qué es la historia cultural? Barcelona: Paidós, 2006.

CABRUJA, Teresa. Cómo construimos el mundo: relativismo, espacios de relación y narratividad. Anàlisi, núm.25, p.61-94, 2000.

CASANOVAS, Josep; COLLELLDEMONT, Eulàlia. La fachada de la escuela. La imagen de la enseñanza en los films documentales de inauguración de grupos escolares durante la dictadura de Primo de Rivera. En: DÁVILA, Paulí; NAYA, Luis M. Espacios y patrimonio educativo. Donostia: Erein, 2016, p.663-678.

; GÓMEZ, Anna. Una escola davant la càmera cinematogràfica. La inauguració de l'edifici del grup escolar de Vinyoles a través d'un film documental de 1928. Ausa, n. 179, 2017. (en prensa).

CATASÚS, Aleix. Josep Maria Pericas i Morros. Arquitecte noucentista (Vic, 1881 Barcelona, 1966). Vic: Patronat d'Estudis Osonencs, 2016.

COLLELLDEMONT, Eulàlia (coord.). Investigar la Història de l'Educació amb Imatges. Vic: Eumo, 2014.

GÓMEZ, Anna. La participación del arte y la literatura en la construcción discursiva de una historia de la educación. Revista Memoria e Historia de la Educación, 2017. (en prensa)

. Fonaments metodològics d'investigar amb les imatges. Referències des de la investigación. En: COLLELLDEMONT, Eulàlia (coord.). Investigar la Història de l'Educació amb Imatges. Vic: Eumo, 2014.

SÁNCHEZ-BIOSCA, Vicente; TRANCHE, Rafael. NO-DO. El tiempo y la memoria. Madrid: Catedra, 2006. 